\title{
In situ and ex situ conservation gap analyses of crop wild relatives from Malawi
}

\author{
Nolipher Khaki Mponya $($ D $\cdot$ Tembo Chanyenga • Joana Magos Brehm • \\ Nigel Maxted
}

Received: 20 April 2020/Accepted: 16 September 2020/Published online: 27 September 2020

(C) The Author(s) 2020

\begin{abstract}
The study analysed the conservation gaps of the priority crop wild relatives (CWR) taxa for Malawi in order to contribute to the development of a harmonized conservation strategy that helps secure the priority CWR under in situ and ex situ. We used taxa distribution modelling, complementarity analysis and ecogeographic land characterization map to analyse spatial diversity and distribution of 123 priority taxa across different adaptive scenarios. We identified areas of observed and predicted richness, the minimum number of protected areas (PAs) that conserve the broadest ecogeographic diversity in situ and the minimum number of grid cells that capture highest diversity outside PAs to recommend the establishment
\end{abstract}

Electronic supplementary material The online version of this article (https://doi.org/10.1007/s10722-020-01021-3) contains supplementary material, which is available to authorized users.

N. Khaki Mponya ( $\square)$

Malawi Plant Genetic Resources Centre, Chitedze

Agricultural Research Station, P.O. Box 158, Lilongwe,

Malawi

e-mail: noliemponya@yahoo.com

N. Khaki Mponya $\cdot$ J. Magos Brehm $\cdot$ N. Maxted College of Life and Environmental Sciences, School of Biosciences, University of Birmingham,

Edgbaston, Birmingham B15 2TT, UK

T. Chanyenga

Forest Research Institute of Malawi,

P.O. Box 270, Zomba, Malawi of genetic reserves. We then analysed the representativeness of the conserved ecogeographic diversity of target taxa in ex situ collections to identify ex situ conservation gaps and advise for priority areas for ex situ collections. For the 123 taxa, $70.7 \%$ of the total diversity occurs in 36 PAs with $66.8 \%$ of the diversity captured in only 10 complementary PAs. Outside PAs, the broadest diversity was conserved in three grid cells of size $5 \times 5 \mathrm{~km}$. Fifty-three of 123 taxa have ex situ collections with only three taxa having ex situ collections at the Malawi Plant Genetic Resources Centre. The findings of this study will guide formulation of conservation actions for the priority taxa as well as lobbying for active conservation of the same under in situ and ex situ.

Keywords Crop wild relative - Conservation gaps · Genetic reserves · In situ · Ex situ · Protected areas

\section{Introduction}

The global community is currently challenged with feeding an expanding human population (FAO 2018; UN 2017; UN 2019). This puts more pressure on already limited resources amidst increased climatic shocks, which have destroyed crops, associated biodiversity and rendered some agricultural land unproductive. The calls for building up resilient production systems have been echoed in the Sustainable 
Development Goals (SDGs) 2 and 15 that target reducing hunger, environmental degradation and loss of biodiversity (FAO 2015; UN 2015; UNDP 2019). Contribution of plant diversity to food security and its sustainable conservation has received much recognition by many other international bodies such as the Food and Agricultural Organization of the United Nations (FAO 2012), the International Treaty on Plant Genetic Resources for Food and Agriculture (FAO 2009) and Convention on Biological Diversity (CBD 2019).

Crop wild relatives (CWR) have potential use in crop improvement (Hajjar and Hodgkin 2007; Vincent et al. 2013). Many crops cultivated in the Southern African Development Community (SADC) region and of global importance such as cotton, wheat, maize, coffee and rice have benefited from adaptive traits originating from CWR (Brar 2005; Edmé et al. 2005; Hajjar and Hodgkin 2007; Vincent et al.2013; Allen et al. 2017; Allen et al. 2019). However, their conservation has been grossly passive with very low representation in many gene banks (CastañedaÁlvarez et al. 2016; Phillips et al. 2016; ContrerasToledo et al. 2019).

Recognizing the need for improved crop production to meet with increasing food demand in the face of unprecedented livelihood damage and biodiversity loss, the SADC region developed a regional inventory of CWR potential for crop improvement (Allen et al. 2019). Currently, the region is developing a CWR conservation strategy in an effort to link conservation and utilization of CWR (Magos Brehm et al. in prep). Further, the 16 SADC member states have a significant contribution in the implementation of the regional strategy by developing their own national strategies that resonate with regional conservation priorities. At present, only Zambia, Mauritius and South Africa have such strategies in place (Ministry of Agriculture 2016; Ng'uni et al. 2017; Bissessur et al. 2019; Holness et al. 2019). Malawi has about 6000 plant taxa excluding the bryophytes and 446 CWR out of which 277 are priorities for conservation based on various criteria including the economic importance of the related crop, their potential use in crop improvement, threat status, native status, taxon national and global distribution (Mponya et al. 2020). National stakeholders in nature conservation and agrobiodiversity community agreed upon the prioritization criteria and methodology. In order to sustainably conserve these resources, Malawi plan to develop a national conservation strategy for the conservation of priority CWR. Having a stand alone CWR strategy has been found to act as a catalyst to a more systematic in situ and ex situ conservation helping reduce loss of these valuable resources (Magos Brehm et al. 2017a). Complementary conservation helps conserve the broadest range of CWR taxa (Maxted et al. 1997, 2015), and with 126 terrestial protected areas in Malawi, there is potential to update management plans in order to accommodate CWR active conservation. However, the current status is that the country lacks knowledge of the distribution of CWR diversity and of the precise locations where conservation that could capture maximum diversity could be designated. In addition, ex situ conservation gaps for the priority taxa are not yet known. The lack of such fundamental information deterred conservation efforts of CWR in Malawi as this input to conservation planning and development of the national conservation strategy (Magos Brehm et al. 2017a).

Thus the aim of this study was to undertake gap analyses of the CWR of Malawi, through (a) analysing the spatial distribution of priority CWR diversity for Malawi; (b) modelling the potential distribution of priority taxa; (c) identifying the minimum number of complementary potential in situ sites within protected areas (PA) that could conserve the broadest range of ecogeographic diversity in situ; (d) identifying locations outside the PAs with high CWR presence where non-PA in situ conservation or novel PAs could be established; and (e) identify locations where priority CWR for ex situ collections could be sampled.

\section{Methods}

Occurrence data collation, verification and quality check

To achieve the above aims, methods adapted from Magos Brehm et al. (2017a) and widely used at national and global level CWR conservation were applied (e.g. Hunter and Heywood 2011; Fielder 2015; Castañeda-Álvarez et al. 2016; Phillips et al. 2016; Taylor et al. 2017; Contreras-Toledo 2018).

The standard template for collation of CWR distributional data was used (Magos et al. 2017b) for the 123 priority CWR taxa (Mponya et al. 2020). Not all 
priority CWR taxa are included in the current eFlora of Malawi (Hyde et al. 2018) and therefore additional occurrence data was obtained from institutions holding Malawi plant herbarium specimen, accessions and other plant information. Such include Royal Botanical Gardens - Kew herbarium and Kew.org/herbcat/navigator.do (2017); Bioversity Collecting Missions Database (Bioversity International 2016); Global Biodiversity Information Facility (GBIF 2017); and Genesys Global Portal on Plant Genetic Resources (2016), National Herbarium and Botanic Gardens of Malawi and the Malawi Plant Genetic Resources Centre (MPGRC). Since $67 \%$ of the records did not have associated locality data, the initial stage was georeferencing of these records using Google Maps (https://maps.google.com/) and a national gazetteer (https://www.diva-gis.org/gdata). Records with coordinates other than decimal degrees were converted using Canadensys (https://data.canadensys.net/tools/ coordinates). Geographic outliers were filtered in DIVA-GIS version 7.5.0 (https://www.diva-gis.org) (Hijmans et al. 2012). Occurrence data was then organised in FAO-Bioversity passport descriptors format (FAO-Bioversity 2012). Quality of georeferencing of the collection sites was assessed using the GEOQUAL tool of the CAPFITOGEN Version 2.0. package that enables to assess the quality of the geographic coordinates (COORDQUAL), suitability of the indicated sites (SUITQUAL) and quality of the location information (LOCALQUAL) (Parra-Quijano et al. 2016). Occurrence records with total quality (TOTALQUAL) above 50\% were used for this study.

Distribution and ecogeographic diversity analyses

Observed taxa distribution and sampling bias were mapped in DIVA-GIS 7.5.0 (Hijmans et al. 2012) for 1621 records with TOTALQUAL $>50 \%$ for a grid cell size of approximately $10 \times 10 \mathrm{~km}$. The potential taxa distribution and richness were obtained using the Maximum Entropy (MaxEnt) algorithm (Phillips et al. 2006) and circular buffer $\left(\mathrm{CA}_{50}\right)$ in ArcMap 10.4.1 (ESRI 2015; Hijmans and Spooner 2001; Contreras Toledo et al. 2019).

Taxa distribution modelling

Potential taxa distribution was estimated by individual distribution models generated for taxa (Table S2) with $\geq 10$ occurrence records in MaxEnt (Phillips et al. 2006; Elith et al. 2006; Hernandez et al. 2006) based on individual sets of ecogeographic variables (Table S1) from Worldclim (https://www.worldclim. org/bioclim) and by circular buffer $\left(\mathrm{CA}_{50}\right)$ for taxa with $<10$ records. Random forest was used to select variables for each of three categories (bioclimatic, edaphic and geophysical with a cell size of $5 \times 5 \mathrm{~km}$ ( $\approx 2.5$ arc minutes at the Equator)) for each taxon in SelecVar (Parra-Quijano et al. 2016). To reduce dimensionality, Bivariate correlation analysis was run in SelecVar and only variables with weak correlation (Pearson value of $\leq 0.3$ ) or not correlated (Pearson value $=0$ ) were used to generate species distribution models for each taxon (Table S1).

Cross validation test and maximum training sensitivity plus specificity threshold were applied. Taxa with $\geq 50$ occurrence records used 10 replications and 5 replications for taxa with $\geq 10$ records. Models that had; (1) average area under the Test ROC Curve [(ATAUC) > 0.7]; (2) standard deviation of ATAUC (STAUC) below 0.15 ; (3) proportion of potential distribution area with standard deviation above 0.15 (ASD15) is below $10 \%$ were considered stable and used for estimating potential taxa distribution (Ramírez-Villegas et al. 2010; Liu and Matt 2016; Contreras Toledo et al. 2019). For the taxa that did not pass the MaxEnt models validation criteria above and for taxa with $<10$ occurrence records, a circular buffer method was applied adapting a $19 \mathrm{~km}$ buffer diameter for Malawi based on country size. For studies targeting larger areas, a $50 \mathrm{~km}$ circular buffer $\left(\mathrm{CA}_{50}\right)$ was considered (e.g. Hijmans and Spooner 2001; Contreras Toledo et al. 2019).

\section{Complementarity analysis}

Complementarity analysis was run in CAPFITOGEN with the Complementa tool at a resolution of $5 \times 5 \mathrm{~km}$ (approximately 30 arc segment at the Equator). PAs network data for Malawi (UNEPWCMC 2019) was used in Complementa to identify PAs containing highest taxa diversity and those with large number of unique taxa to propose for genetic reserves. For PAs with similar number of unique taxa, random selection was applied. The complementary analyses maps were visualised in DIVA-GIS 7.5.0 (Hijmans et al. 2012) and ArcMap 10.4.1 (ESRI 2015). A grid cell analysis was also run in Complementa and 
identified hotspot grid cells outside PAs that would optimize ex situ collections as well as conserve CWR diversity outside PAs.

Ecogeographic land characterization map

Finally, a generalist Ecogeographic Land Characterization (ELC) map that defines general land characteristics where taxa could occur was produced with the ELCmapas tool in CAPFITOGEN 2.0, using the elbow method, with a cell size of $5 \times 5 \mathrm{~km}$ (approximately 2.5 arc minutes at the Equator), as described by Parra-Quijano et al. (2016). Eleven variables were used to produce the ELC map. Variables were selected in SelecVar as described in taxa distribution modelling.

\section{Conservation gaps}

Average Maxent models for each taxon and potential distribution map produced by a circular buffer $\left(\mathrm{CA}_{50}\right)$ method were combined in DIVA GIS.7.5.0 to create potential species distribution map for 123 priority CWR taxa. The observed species distribution map was subtracted from the potential distribution map. In situ conservation gaps were estimated by (1) comparing the coverage of the predicted richness already passively conserved in situ in the PAs and that which is outside of PAs; (2) comparing number of ELC zones captured in PAs against those outside PAs and (3) by comparing populations of taxa conserved in PAs versus that outside of PAs.

The taxa and ecogeographic diversity represented in genebank accessions held by MPGRC and international genebanks (Table5b) were analysed using Representa tool in CAPFITOGEN tools (Parra-Quijano et al. 2016). Adaptive scenarios (ELC zones) from ELC map developed earlier were used to divide the ELC map into four classes (Low, medium, medium to high and high) based on their frequency on ELC map as well as based on collections. Ex situ conservation gaps were identified by comparing representation of the ELC classes in the ex situ collections held at the MPGRC and international genebanks and by comparing the diversity conserved ex situ against that present in situ.

\section{Results}

Observed and potential taxa diversity and distribution

Analyses were done on 123 priority taxa out of the 277 priority taxa included in the national inventory, as there were no data for the remaining priority CWR. Hotspots of CWR taxa were observed in the districts of Zomba (42 taxa) in the Southern Region with part of the diversity occurring in Zomba Forest Reserve and extends outside the protected area, Dedza (22) in the Centre and Mzimba (25) District in the Northern Region bordering Kaning'ina Forest Reserve on Nkhata Bay District side (Fig. 1a). These hotspots correspond to the same areas where observational bias was noted (Fig S1).

An average potential distribution map created from the 15 taxa models that passed the validation criteria (Tables S1 and S2) and that from circular buffer (CA50) for the taxa that did not pass the validation criteria and those with $<10$ records indicates wider coverage of diversity of priority CWR in Malawi (Fig. 1b). Most of the diversity was predicted outside of PAs and possibly in cultivated land and settlement areas. In the Northern Region, much of the diversity is predicted in Nyika National Park, Kaning'ina Forest Reserve in the vicinity of Mzuzu city and Mughese and Wilindi Forest Reserves (Fig. 1a). Diversity in Blantyre, Thyolo and Dedza Districts was predicted within the towns raising more concern on the availability of such taxa as the demand for settlement is on increase.

Complementarity analyses

Coverage analysis identified 36 PAs with at least one priority CWR taxon (Fig. S2) and these in total conserve $70.7 \%$ diversity of 123 priority CWR taxa. The 36 PAs represent $63.2 \%$ of the total PAs area in Malawi. However, 32 PAs were identified as complementary (Fig. S3). Within the complementary PAs, $66.83 \%$ of the diversity is conserved in ten (10) PAs. (Fig. 2). Higher numbers of CWR taxa were conserved in South Viphya Forest Reserve (38 taxa), Nyika National Park (36), Mulanje (24) and Zomba (19) Forest Reserves; Lengwe (11) and Kasungu National Parks (seven) (Fig. 2 and Table 1) and the other four PAs had less than seven taxa. The six PAs 


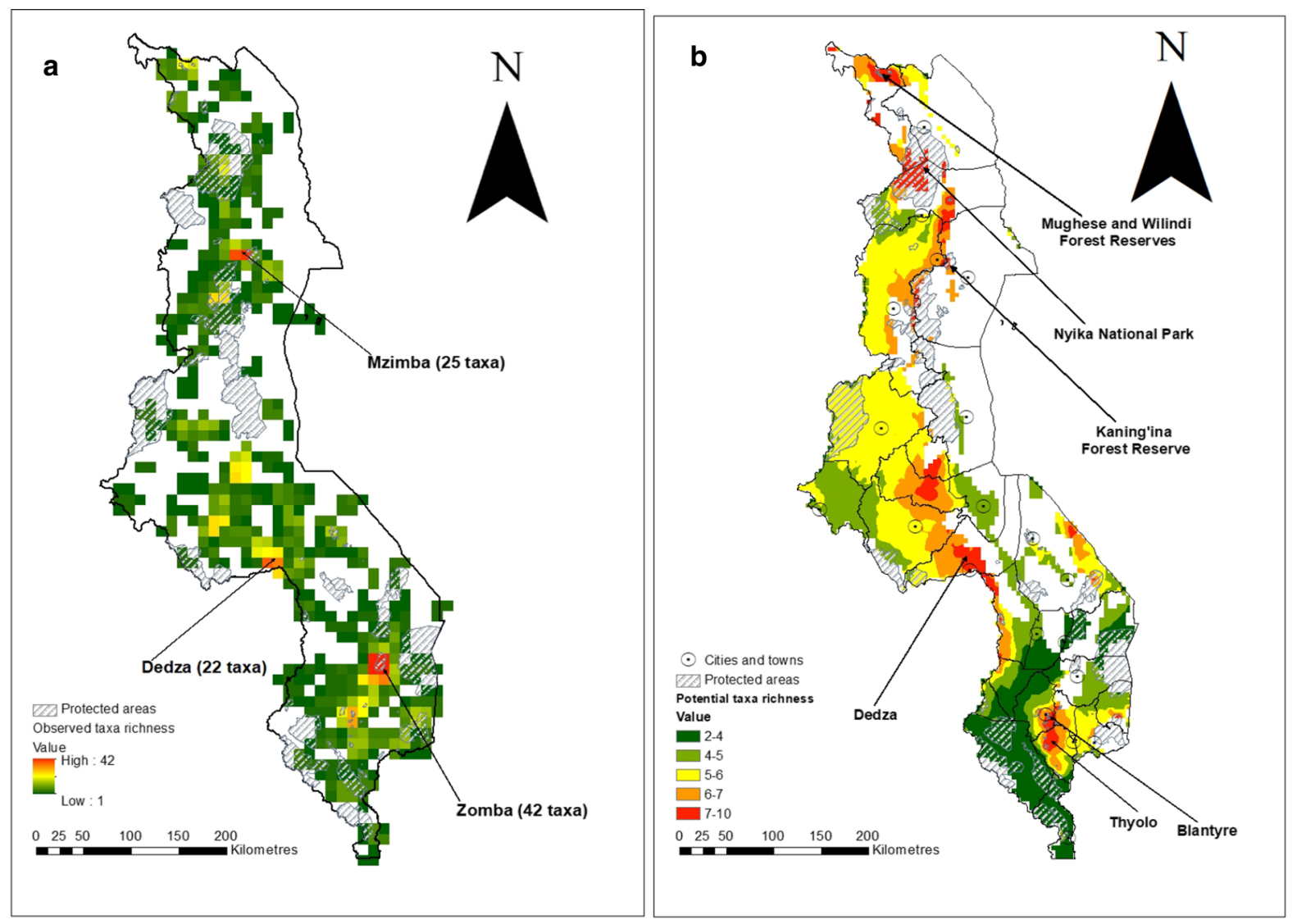

Fig. 1 Observed (a) and potential richness (b) and distribution of priority CWR taxa in Malawi. Grid square size of 0.1degrees $(10 \times 10 \mathrm{~km}$ at the Equator)

with highest diversity had also higher overall taxa occurrences (range of 10-86) (Fig. S2 and Table 1). However, 61 taxa present in these PAs have low $(\leq 3)$ known occurrences (Table 1 and Table S3). Taxa with low population size had on average $75 \%$ of their population located outside PAs (Table S3 and Table S4). Ten (10) taxa recorded a single population (Table S3) which means that they only occur at one site within a PA. Unfortunately, none of these has ex situ collections at MPGRC (Table S5a) and ex situ collections of 11 taxa held at international genebanks (Table S5b) had no duplicates at the MPGRC (Tables S5a). Those with accessions in the international genebanks include Vigna unguiculata (L.)Walp subsp. dekindtiana (Harms) Verdc., V. unguiculata (L.)Walp subsp. pawekiae Pasquet, V. unguiculata (L.)Walp subsp. pubescens (R.Wilczek) Pasquet, $V$. unguiculata (L.)Walp subsp. stenophylla Harms (Mponya et al. 2020). These have potential use in crop improvement and require immediate field exploration for their conservation. These populations are then priority for collection and conservation in ex situ genebanks. Grid cell analyses identified hotspots in Dedza District (Point a), Lilongwe District (point b) and the boundary between Dowa and Ntchisi Districts (point c) in Fig. 2.

Ecogeographic land characterization map

Eleven environmental variables (4 bioclimatic, 4 edaphic and 3 geophysical) were used to generate 27 ELC zones which represented potential adaptive scenarios for 123 priority taxa (Parra-Quijano et al. 2012, 2011). The ecogeographic diversity of 19 ELC zones is passively conserved in complementary PAs (Table S6) and 12 out of the 19 ELC zones are located in the 6 complementary PAs with highest diversity 


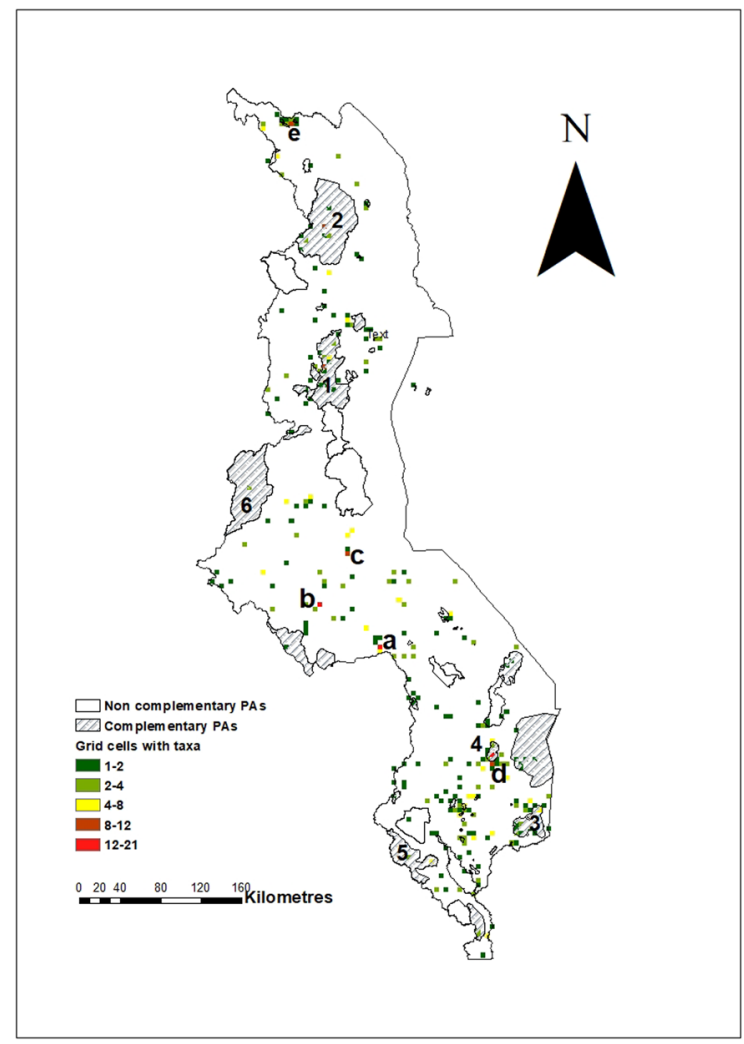

Fig. 2 Complementary network of protected areas that passively conserve priority CWR taxa in Malawi and number of grid cells (size $5 \times 5 \mathrm{~km}$ at the equator) with taxa. Letters refer to grid cells outside protected areas with high number of taxa and numbers refer to 6 ranked complementary protected areas with high number of taxa and potential for genetic reserves

(Table 1; Figs. 3, 4b) and with potential for genetic reserve designation.

Ecogeographic diversity representativeness in ex situ collections and taxa in situ

By percentage, only $25.9 \%$ of the ecogeographic diversity of priority CWR is conserved ex situ and the rest remains in the wild and passively conserved. This diversity represents 53 taxa whose collections are held at MPGRC (102) with 555 accessions held by international genebanks (Table S5a and S5b). The 53 taxa represent ecogeographic diversity of 20 ELC zones (Fig. 4a) and the diversity of 7 ELC zones is not represented. Twelve of the 20 ELC zones are conserved by both MPGRC and international genebanks (Table 2) with ELC zones 0, 8 and 19 being relatively represented in both genebanks collections.
Coincidently, these seem to be ELC zones with high frequency on the ELC map (Table 2). In terms of population size, only ELC zones 0 and 8 had sufficient $(\geq 10 \%)$ representation at MPGRC and the rest had less than $5 \%$ representation to zero (no ex situ collections). The trend was similar to international genebanks but in either case, ELC zone 0 had high representation in both genebanks collections and much of its diversity was also passively conserved in situ (Fig. 4).

By numbers, the MPGRC conserved three of the 53 taxa with ex situ collections and these included Oryza longistaminata, O. barthii and O. punctata (Table S5). With exception of $O$. longistaminata which was categorized as threatened (Vulnerable) by South African plants red listing (2009), taxa threatened at global level such as Coffea ligustroides S.Moore, $C$. salvatrix Swynnerton \& Phillipson, and C. arabica $\mathrm{L}$. (wild types) and Prunus africana (Hook.f.) Kalkman, (IUNC 2018) had no ex situ collections held by external gene banks either, had restricted geographic distribution and had small population size (Table S3 and Table S4).

Oryza and Vigna have more collections than other taxa. ELC zones 19 and 20 (Fig. 4a) had extensive collections by external partners. Coincidently, the most collected ELC zones happened to be represented in situ especially in PAs with the highest diversity (Table 1).

In situ conservation gaps

The ecogeographic diversity of 19 ELC zones is passively conserved in 36 PAs, however only three ELC zones have relatively high occurrence $(>20)$ frequency in these PAs (Fig. 4b). This agrees with Tables S3 and S4 that indicated highest number of taxa having greater proportion of their population outside PAs. Figure 5 indicated similar outputs of having most of the predicted hotspots outside PAs with exception of potential richness captured in Nyika National Park, South Viphya and Mughese Forest Reserves in the Northern Region.

In Central Region, hotspots were in Dedza (a), Dowa (b), Ntchisi (c) and Ntcheu (d), Districts (Fig. 5). In the Southern Region, hots pots were in Mangochi, Blantyre, and Thyolo Districts (Fig. 5). The diversity conserved in situ covers 87 taxa out of 123. Ecogeographic diversity that does not occur in 
Table 1 Occurrence and diversity coverage of priority taxa across six priority complementary protected areas (PAs)

\begin{tabular}{|c|c|c|c|c|c|c|}
\hline Rank & $\begin{array}{l}\text { Complementary } \\
\text { PA }\end{array}$ & $\begin{array}{l}\text { Number of CWR } \\
\text { occurrence records }\end{array}$ & $\begin{array}{l}\text { Number of CWR } \\
\text { occurring in a PA }\end{array}$ & $\begin{array}{l}\text { Number of unique } \\
\text { CWR in a PA }\end{array}$ & ELC zones & $\begin{array}{l}\text { Total area of } \\
\text { each PA }\left(\mathrm{km}^{2}\right)\end{array}$ \\
\hline 1 & South viphya & 49 & 38 & 38 & $0^{*}, 18^{*}, 19,21^{*}, 24,25$ & 1147.8 \\
\hline 2 & $\begin{array}{l}\text { Nyika national } \\
\text { park }\end{array}$ & 65 & 37 & 36 & $0^{*}, 18,19^{*}, 24$ & 3092.32 \\
\hline 3 & $\begin{array}{l}\text { Mulanje forest } \\
\text { reserve }\end{array}$ & 59 & 26 & 24 & $0^{*}, 9^{*}, 15^{*}$ & 552.09 \\
\hline 4 & $\begin{array}{l}\text { Zomba forest } \\
\text { reserve }\end{array}$ & 86 & 33 & 19 & $0 *$ & 59.57 \\
\hline 5 & $\begin{array}{l}\text { Lengwe national } \\
\text { park }\end{array}$ & 15 & 12 & 11 & $0^{*}, 5^{*}, 7^{*}, 8^{*}$ & 928.19 \\
\hline 6 & $\begin{array}{l}\text { Kasungu } \\
\text { national park }\end{array}$ & 10 & 7 & 7 & $18,19^{*}, 21,22,24,25^{*}$ & 2358.62 \\
\hline
\end{tabular}

*Means ELC zones where taxa were observed

Protected areas coverage data source: protected planet (https://protectedplanet.net/, (UNEP-WCMC (2019))

Diversity represents both species diversity and ecogeographic diversity

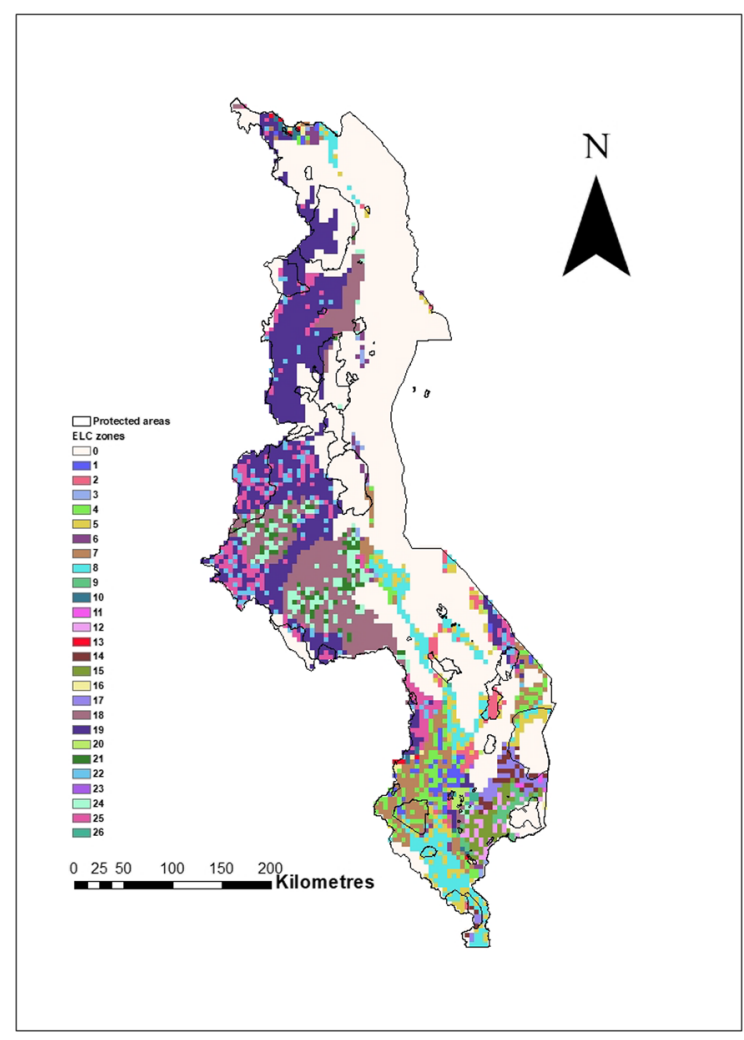

Fig. 3 ELC map for Malawi composed of 27 ELC zones. Each zone represents a combination of environmental variables

PA include that falling in ELC zones of 1, 3, 4, 6, 11, 12, 16 and 26 (Table S6 and Fig. 4b).

\section{Discussions}

In Malawi, the diversity of priority CWR has a wide geographic coverage and no CWR populations are actively conserved in existing PAs. A relative high amount of diversity (70.7\%) is passively conserved in 36 PAs, and the remainder occurs outside PAs. Outside PAs, hotspots were observed in grid cells located in Dedza and Lilongwe Districts and the boundary between Ntchisi and Dowa Districts. These sites are documented as forest reserves in the Protected Planet database although their polygons were not yet available when the study was conducted. It is therefore likely that the percentage of diversity passively conserved in situ for 123 taxa is $>70.7 \%$.

Having a huge amount of diversity being already passively conserved in PAs provides for a great opportunity to advocate for an active in situ conservation given that the establishment of genetic reserves will require minimal negotiations as PAs would only have to adapt their management plans to accommodate CWR conservation (Maxted and Kell 2009).

For an active in situ conservation of priority taxa in Malawi, 10 PAs could be potential for active in situ conservation as they passively conserve more that $60 \%$ of the priority CWR taxa for which data are available ie they capture 73 out of 123 priority taxa. However, only 6 PAs (South Viphya, Mulanje and Zomba Forest Reserves; Nyika, Kasungu and Lengwe 
a

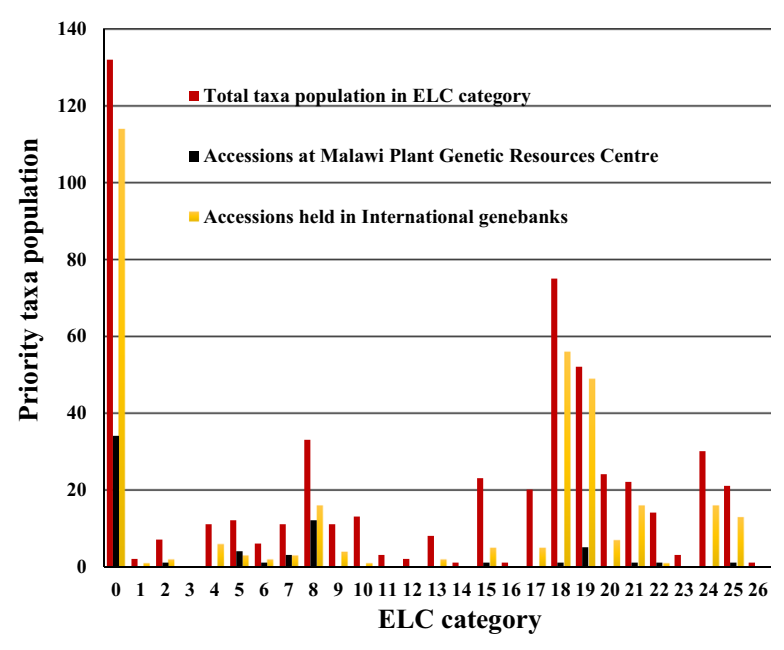

b

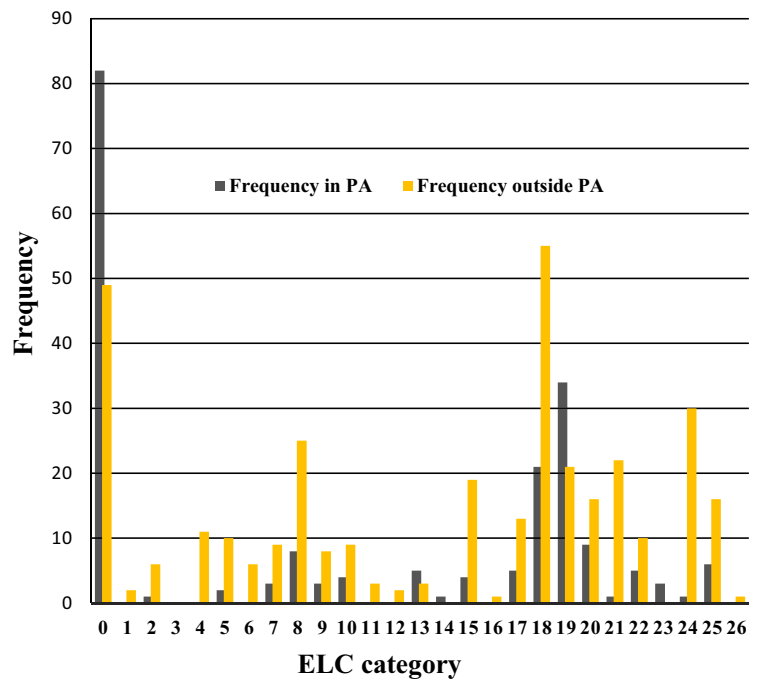

Fig. 4 Ex situ (a) and in situ (b) conservation gaps of priority CWR taxa based on taxa representation at national and international genebanks and taxa passively conserved in situ in PAs and outside PAs across the 27 ELC categories

Table 2 ELC categories classification based on taxa collections and the frequency of ELC zones on the ELC map for future taxa exploration

\begin{tabular}{llll}
\hline ELC category & $\begin{array}{l}\text { Classification by frequency of taxa occurrence } \\
\text { (based on National gene bank collections) }\end{array}$ & ELC category & $\begin{array}{l}\text { Classification by frequency } \\
\text { of the category on ELC map }^{\mathrm{b}}\end{array}$ \\
\hline $\begin{array}{l}1,3,4,9,10,11,12,13,14,16,17, \\
20,23,24,26\end{array}$ & Not collected & Not applicable & Not applicable \\
$2,6,15,18,21,22,25$ & Low** & $3,10,11,13,16,23,26$ & Low \\
Not applicable & Medium-low & $1,6,9,12,14,19,20$ & Medium-low \\
5,7 & Medium-high & $2,4,15,21,22,24$ & Medium-high \\
$0,8,19$ & High & $0,5,7,8,18,19,25$ & High \\
\hline
\end{tabular}

** Low refers to classification where $<5$ samples were collected

${ }^{a}$ Refers to the frequency of ELC classes as observed in the ex situ collections

${ }^{\mathrm{b}}$ Refers to the frequency of ELC category on ELC map

${ }^{c}$ ELC Zones categories not represented in the ex situ collections of the national gene bank

National Parks) have; (1) stable taxa populations with high numbers of occurrences (range of 10-86), (2) high number of unique taxa not found in any of the other complementary PAs; (3) they represent unique adaptations for the taxa (being located in different agro ecological zones), (4) harbour rare taxa. For efficiency and cost effectiveness, these complementary PAs should be considered for genetic reserves.

Zomba Forest Reserve is of particular interest because it has a small coverage area $\left(59.57 \mathrm{~km}^{2}\right)$ and yet has the highest (86) population of taxa and taxa richness (33) with 19 unique taxa that only occur in this complementary PA and taxa diversity pattern extends outside its borders as well. This was not surprising because Rapid Botanical Surveys conducted in the Shire River Basin in 2016 reported that Zomba-Malosa Forest Reserve harbours taxa of significant global uniqueness and has the fourth-highest level of globally-rare, restricted range taxa (Shire River Management Programme 2017).

The overflow taxa richness was also predicted in Mughese, Wilindi and Kaning'ina Forest Reserves 


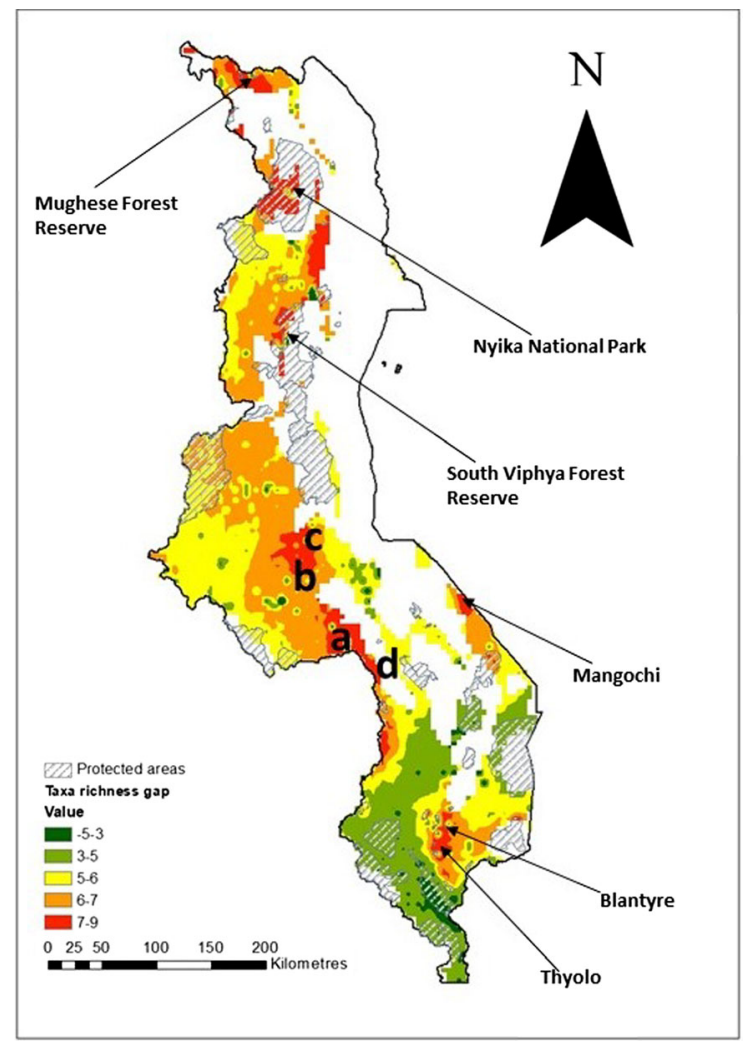

Fig. 5 Taxa richness gaps for further exploration in Malawi. Grid square size of 0.1 degrees $(10 \times 10 \mathrm{~km}$ at the equator). Labelled sites had the highest number of predicted taxa than observed. Letters represent taxa hotspots outside PA

and Nyika National Park where diversity extends beyond borders of these PAs. It is therefore, advisable that any actions to establish the genetic reserves in these areas should endeavour to use natural species distribution other than the nominal boundaries in order to ensure minimal disturbance to the biosphere that might cause loss of species fitness (Hunter and Heywood 2011 Chapter 9). Genetic reserves for the other five PAs may be considered in localized grids of $10 \times 10 \mathrm{~km}$ considering that they have large area coverage (500-3092 $\mathrm{km}^{2}$ ) which make them practically impossible to effectively monitor the species population (Maxted and Kell 2009) and difficult to manage the associated threats (Hunter and Heywood 2011 Chapter 9).

It is important to note that populations of $72 \%$ of individual taxon occurring across PAs were less than 5 with $32 \%$ having population range of $1-2$. It is particularly concerning that these taxa may only occur once or twice in a PA and may be prone to localized threats. It was also noted that a large proportion $(>75 \%)$ of the population of these taxa was outside PAs. Efforts to survey their occurrence in other sites predicted by species modelling can help establish the present population and this helps in designing an effective monitoring mechanism (Iriondo et al. 2008).

Of particular interest are taxa with no population in PAs (Table S3). Probably the indicated ELC zones captured in PAs in which they are present should be used for surveying as these represent environments into which they are potentially adapted. Diversity outside PAs was observed in Thyolo, Dedza, Ntchisi, Dowa and Chitipa Districts (Figs. 1 and 5). Some of these sites are near and or at the centre of the towns (Fig. 1) and having such diversity not conserved elsewhere is a risk.

When compared with the observed diversity, it was also noted that more sites in Malawi were predicted to have CWR and much of the diversity was predicted outside PAs. This could mean that Malawi is under surveyed. In order to secure a broad range of the diversity of taxa outside PAs, these sites should be explored for genetic reserves. In that case, it would require three grid cells of $10 \times 10 \mathrm{~km}$ to conserve this diversity of priority CWR outside PA given that other grids with highest taxa are within and or close to PAs. Although these sites occur within or close to towns, efforts to assess their suitability for establishing genetic reserves should not be undermined as some of these towns have gardens with natural vegetation, forest reserves that could be potential for active in situ conservation of the priority CWR taxa. However, for effective conservation, priority must be given for ex situ collections because taxa present in these sites are likely to be more threatened than those in PAs due to changes in land use that may result to habitat loss. There is more ecogeographic diversity of priority CWR outside PA than within existing PA. Therefore conserving this diversity ensures capturing of both low represented ELC zones in PAs and ELC zones that are rare.

The results of taxa representativeness in ex situ conservation were a true reflection of global gap analysis outcomes (Castañeda-Álvarez et al. 2016). Priority taxa are poorly represented at MPGRC. Currently, only three taxa (Oryza barthii, O. longistaminata and $O$. punctata) out the 277 priority taxa have ex situ collections at the MPGRC and this calls 
for urgent action. When possible, the existing $555 \mathrm{ex}$ situ accessions of the 50 CWR taxa held at international genebanks should be retrieved to have their duplicates conserved at MPGRC. O. punctata is under-represented with three records at MPGRC and zero collections reported for external genebanks. Even within Malawi, this taxon is rare with only two occurrence sites hence the need to put effective conservation measures before it disappears.

Although the large amount of priority CWR diversity seems to be passively conserved in situ, under representation in the MPGRC defeats the very purpose of utilization that is the focus of CWR conservation. The need to conserve such taxa ex situ is paramount if we are to facilitate access and utilization in crop improvement as well as further exploration by other users (Hunter and Heywood 2011 Chapter 1).

Ex situ collections are needed for 121 taxa without collections at MPGRC and the same applies to 154 priority taxa not included in this study. Predicted hotspots outside PAs should be targeted in order to capture broad range of diversity with minimal expeditions to safeguard priority CWR taxa before they go extinct due to climate change and anthropogenic related threats.

Ecogeographic diversity of ELC zone 0 had more than 100 accessions under ex situ conservation and with high frequency of occurrence in PAs compared to other ELC zones (Table 2; Figs. 3, 4a, b). Rare ELC zones represent unique potential adaptive scenarios and taxa from such environments might represent unique genes (Parra-Quijano et al. 2016) and should be priority for ex situ collections. However, for wider ecogeographic diversity representativeness, Fig. 5 and Table 2 should guide the ex situ collection missions as conserving the full range of diversity ensures unique genes are also captured (Parra-Quijano et al. 2016).

Although species seed dispersal mechanisms and geographic barriers may influence potential species distribution, potential richness based on MaxEnt models and circular buffer $\left(\mathrm{CA}_{50}\right)$ closely resembled the pattern of observed richness and therefore gave a true reflection of the diversity distribution in Malawi. Taxa richness was predicted in sites previously observed through grid cell analysis signifying that the richness in these sites could be one aspect of the observational bias noted in this study. The reason for this could be that most collectors and botanists tend to concentrate their collections in areas where diversity is high (Hunter and Heywood 2011). However, more work should be done to establish the status of the remaining 154 priority taxa excluded from this study as some of these taxa have potential use in crop improvement and such include Brassica juncea (L.) Czern., Gossypium barbadense L., Olea europaea L. subsp. cuspidata (Wall. ex G.Don) Cif (Mponya et al. 2020). Predicting occurrence and distribution of the priority taxa was the first step. As a follow up to this study, we recommend the following conservation actions:

1. Conduct field surveys to establish the current distribution of 123 priority taxa targeting potential hotspots as predicted by the SDMs and circular buffer $\left(\mathrm{CA}_{50}\right)$ and for the distribution of 154 taxa not included in this study.

2. Assess the status of taxa with fewer populations (1-4) in both PAs and outside the PAs in order to establish their current status and design sustainable measures for their conservation.

3. Assess the status and suitability of the six complementary PAs with highest diversity of priority CWR taxa for establishing genetic reserves based on the recommendations of Dulloo et al. (2008) and the quality standards described in Iriondo et al. (2012).

4. Initiate negotiations for border expansion for the suitable complementary PAs whose diversity spans beyond the set boundaries and this should only be considered if the diversity of CWR in question is not conserved within the borders of the PAs.

5. Initiate urgent ex situ collection expeditions for the 121 taxa not represented in the MPGRC and for O.punctata that is underrepresented targeting:

a. Hotspots outside protected areas first and then rare adaptive environments (ELC zones) see Figure S2 and Table 2.

b. Taxa whose largest $(>60 \%)$ population is outside PAs (Table S4).

6. Plan for retrieval of the ex situ collections of the taxa held at international genebanks but have no duplicates at MPGRC and duplicate these with the SADC gene bank.

7. Update findings in this paper and recommendations periodically based on available data and or information. 


\section{Conclusion}

The outcomes of this study provide a foundation for conservation planning for CWR in Malawi. Although only based on analysis of 123 priority CWR taxa, they are also useful for the other taxa not included in this study as the methods used are applicable to both. Understanding that conservation needs for CWR and that of users may change overtime, the recommendations provided on these findings should be regarded as guidance and where more information is made available, they can be modified. Considering that this nature of work is holistic, the views of stakeholders during reserve evaluation should not be undermined and the implementation of the recommended conservation actions should be a shared responsibility. Any support to ensure that these resources are safeguarded brings a difference. Lastly, the results provide an opportunity for other SADC member states to draw lessons from; having a number of member states without knowledge of current conservation gaps of CWR.

Acknowledgements Authors acknowledge the financial support of the Malawi Government through the Agricultural Productivity Program for Southern Africa (APPSA) that enabled this study. We also thank Dr. Jade Phillips, Dr. Aremi R. Contreras-Toledo and Prof. Mauricio Parra-Quijano for their support during data analyses.

Author's contribution NKM, JMB and NM conceived the ideas and designed the study; NKM. collated data. NKM analysed the data in consultation with JMB. NKM, JMB and NM interpreted the results and wrote the paper. TC reviewed and commented on the content of the paper.

Funding The Malawi Government provided funding for this study as a scholarship to the corresponding author.

Availability of data and materials Data used in this study is available from the Malawi Plant Genetic Resources Centre (National Gene bank) and currently accessed directly through contacting the corresponding author.

\section{Comiplance with ethical standards}

Conflict of interest The authors declare no conflict of interest for this work.

Ethical approval The study was on plants and not on animal and human beings.

Consent to publish Authors agree to publish this work.
Code Availability Not applicalbe.

Open Access This article is licensed under a Creative Commons Attribution 4.0 International License, which permits use, sharing, adaptation, distribution and reproduction in any medium or format, as long as you give appropriate credit to the original author(s) and the source, provide a link to the Creative Commons licence, and indicate if changes were made. The images or other third party material in this article are included in the article's Creative Commons licence, unless indicated otherwise in a credit line to the material. If material is not included in the article's Creative Commons licence and your intended use is not permitted by statutory regulation or exceeds the permitted use, you will need to obtain permission directly from the copyright holder. To view a copy of this licence, visit http://creativecommons.org/licenses/by/4.0/.

\section{References}

Allen E, Kell S, Magos Brehm J, Gaisberger H (2017) Priority CWR species of the SADC region. Harvard Dataverse, V1.https://doi.org/10.7910/DVN/HSXUVE

Allen E, Gaisberger H, Brehm JM, Maxted N, Thormann I, Lupupa T, Kell SP, Dulloo ME (2019) Acrop wild relative inventory for Southern Africa:a first step in linking conservation and use of valuable wild populations for enhancing food security. Plant Genet Resour. https://doi. org/10.1017/S1479262118000515

Bioversity International (2016) Bioversity International. Retrieved from collecting missions: https://bioversity. github.io/geosite/\#searc. Accessed 20 Nov 2016

Bissessur P, Baider C, Boodia N, Badaloo G, Bégué J, Jhumka Z, Meunier A, Mungroo Y, Gopal V, Kell SP, Magos Brehm J, Thormann I, Jaufeerally-Fakim Y (2019) Crop wild relative diversity and conservation planning in two isolated oceanic islands of a biodiversity hotspot (Mauritius and Rodrigues). Plant Genet Resour 17(2):174-184

Brar D (2005) Broadening the genepool and exploiting heterosis in cultivated rice. In: Toriyama K, Heong K, Hardy B (eds) Rice is life: scientific perspectives for the 21 st Century. Proceedings of the world rice research conference, Tokyo and Tsukuba, Japan, 4-7 November 2004. Tokyo and Tsukuba

Castañeda-Álvarez NP, Khoury CK, Achicanoy HA, Bernau V, Dempewolf H, Eastwood RJ, Guarino L, Harker RH, Jarvis A, Maxted N, Müller JV, Ramirez-Villegas J, Sosa CC, Struik PC, Vincent H, Toll J (2016) Global conservation priorities for crop wild relatives. Nat Plants 2:16022

CBD (2019) The convention of biological diversity secretariat; convention on biological diversity communications. https://www.cbd.int/doc/notifications/2015/ntf-2015-092gspc-en.pdf. Accessed 30 Jan 2019

Contreras-Toledo AR (2018) A crop wild reative conservation strategy for Mexico. Ph.D. Thesis, University of Birmingham

Contreras-Toledo A, Cortés-Cruz M, Costich D, Rico-Arce M, Magos Brehm J, Maxted N (2019) Diversity and 
conservation priorities of crop wild relatives in Mexico. Plant Genet Resour 17(2):140-150. https://doi.org/10. 1017/S1479262118000540

Dulloo M, Labokas J, Iriondo J, Maxted N, Lane A, Laguna E, Javis A (2008) Conserving plant genetic diversity in protected areas. In: Maxted N, Iriondo JM (eds) Genetic reserve location and design. CABI publishing, Wallingford

Edme' SJ, Miller JD, Glaz B, Comstock PY (2005) Genetic contribution to yield gains in the Florida sugarcane industry across 33 Years. Crop Sci J 45(92):97

Elith J, Graham CH, Anderson RP, Dudík M et al (2006) Novel methods improve prediction of species' distributions from occurrence data. Ecography. https://doi.org/10.1111/j. 2006.0906-7590.04596.x

ESRI (2015) ArcMap for desktop release version 10.4.1.Enviornmental Systems Research Institute, Redlands, Califonia

FAO (2009) Food and Agriculture Organization of the United Nations. https://www.planttreaty.org/. Accessed 12 Oct 2017

FAO (2012) Food and agricultural organization of the united nations: synthetic account of the second global plan of action for plant genetic resources for food and agriculture. commission on plant genetic resources for food and agriculture. https://www.fao.org/docrep. Accessed 12 Oct 2017

FAO (2015) Food and Agriculture Organization of the United Nations:the impact of natural hazards and natural disasters on agriculture and food security and nutrition. A call for an action to build resilience livelihood. https://www.fao.org/ 3/a-i4434e. Accessed 10 Dec 2016

FAO (2018) Food and Agriculture Organization of the United Nations: The state of food security and nutrition in the world. https://www.fao.org/3/I9553EN/i9553en.pdf. Accessed 30 Jan 2019

Fieder HV (2015) Developing methodologies for the genetic conservation of the UK crop wild relatives. Ph.D. Thesis,University of Birmingham

GBIF (2017) Global biodiversity information facility. Plant occurrence data sets for Malawi. https://www.gbif.org/ occurrence/search?q=plant $\% 2520$ occurrence $\% 2520$ data $\%$ 2520sets\&country=MW . Accessed 14 Mar 2017

Genesys Global Portal on Plant Genetic Resources (2016) Genesys. https://www.genesys-pgr.org/welcome. Accessed 23 Oct 2017

Hajjar R, Hodgkin T (2007) The use of wild relatives in crop improvement: a survey of developments over the last 20 years. Euphytica 156:1-13

Hernandez PA, Graham CH, Master LL, Albert DL (2006) The effect of sample size and species characteristics on performance of different species distribution modelling methods. Ecography. https://doi.org/10.1111/j.0906-7590. 2006.04700.x

Hijmans RJ, Spooner DM (2001) Geographic distribution of wild potato species. Am J Bot 88:2101-2112

Hijmans R, Guarino L, Mathur P (2012) DIVA-GIS.7.5.0. https://www.diva-gis.org/documentation. Accessed 3 July 2019

Holness S, Hamer M, Magos Brehm J, Raimondo D (2019) Priority areas for the in situ conservation of crop wild relatives in South Africa. Plant Genet Resour 17(2):115-127
Hunter D, Heywood V (2011) Crop wild relatives. Amanual of in situ conservation. In: Hunter D, Heywood V (eds) Bioversity International. Earthscan, London, Washington DC

Hyde M, Wursten B, Ballings P, Coates Palgrave M (2018) Flora of Malawi: species data: list of families. www. malawiflora.com/speciesdata/index.php. Accessed 10 Nov 2018

Iriondo J, Maxted N, Dulloo E (2008) Conserving plant genetic diversity in protected areas: population management of crop wild relatives. CAB international, Wallingford, UK

Iriondo J, Maxted N, Kell S, Ford-Lloyd B, Lara-Romano C, Labokas J, Magos Brehm J (2012) Quality standards for genetic reserve conservation of crop wild relatives. In: Dulloo Mand Maxted N (ed) Agrobiodiversity conservation: securing the diversity of crop wild relatives and landraces. CABI, Wallingford, UK

IUCN (2018) The international union of nature conservation red list of threatened species.https://www.iucnredlist.org. Accessed 30 Nov 2018

Liu C, Newell G, Matt White M (2016) On the selection of thresholds for predicting species occurrence with presenceonly data. Ecol Evol 6(1):337-348. https://doi.org/10. 1002/ece3.1878

Magos Brehm J, Kell S, Thormann I, Gaisberger H, Dulloo M, Maxted N (2017a) Interactive Toolkit for Crop Wild Relative Conservation Planning version1.0. University of Birmingham, Birmingham, UK and Bioversity International, Rome, Italy.htt://www.cropwildrelatives.org/ conservation-toolkit/. Accessed 23 Nov 2019

Magos Brehm J, Kell S, Thormann I, Gaisberger H, Dulloo E, Maxted N (2017b) "Occurrence data collation template v.1”.https://doi.org/10.7910/DVN/5B9IV5, Harvard Dataverse, V1

Maxted N , Kell S (2009) Establishment of a global Network for the In Situ Conservation of Crop Wild Relatives: Status and Needs. Thematic Background Study.https://www.fao.org/ docrep. Accessed 20 Nov 2016

Maxted N, Ford-Lloyd BV, Hawkes JG (1997) Complementary conservation strategies. In: Maxted N, Ford-Lloyd BV, Hawkes JG (eds) Plant genetic conservation: the in situ approach. Chapman and Hall, London, pp 20-55

Maxted N, Avagyan A, Frese L, Iriondo JM, Magos Brehm J, Singer A, Kell SP (2015) ECPGR Concept for in situ conservation of crop wild relatives in Europe. Wild species conservation in genetic reserves working group, European Cooperative Programme for Plant Genetic Resources, Rome, Italy

Ministry of Agriculture (2016) National Strategic Action Plan for the conservation and sustainable use of crop wild relatives in Zambia. https://www.cropwildrelatives.org/ fileadmin/templates/cropwildrelatives.org/upload/ documents/NSAP_Zambia_signed.pdf

Mponya NK, Magombo ZLK, Pungulani L, Magos Brehm J, Maxted N (2020) Development of a prioritised checklist of crop wild relatives for conservation in Malawi. Afr Crop Sci J 28(2):279-311. https://doi.org/10.4314/acsj.v28i2.1

Ng'uni D, Munkombwe G, Mwila G, Dulloo E, Thormann I, Gaisberger H, Maxted N, Magos BJ, Kell S (2017) Technical background document to the national strategic action plan for the conservation and sustainable use of cop wild 
relatives in Zambia“, Harvard Dataverse, V1. https://doi. org/10.7910/DVN/VYZZFF

Parra-Quijano M, Iriondo JM, Torres E (2011) Ecogeographical land characterization maps as a tool for assessing plant adaptation and their implications in agrobiodiversity studies. Genet Resour Crop Evol. https://doi.org/10.1007/ s10722-011-9676-7

Parra-Quijano M, Iriondo JM, Frese L, Torres E (2012) Spatial and ecogeographic approaches for selecting genetic reserves in Europe. In: Maxted N (ed) Agrobiodiversity conservation: securing the diversity 20 of crop wild relatives and landraces. CAB International, Wallinford

Parra-Quijano M, Torres E, Iriondo JM, López F, Molina PA (2016) CAPFITOGEN tools. User manual version 2.0. International Treaty on Plant Genetic Resources for Food and Agriculture. http:// www.capfitogen.net/en/. Accessed 3 July 2019. pp 251

Phillips SJ, Anderson RP, Schapire RE (2006) Maximum entropy modelling of species geographic distributions. Ecol Model. 190(3-4):231-259

Phillips J, Asdal Å, Magos Brehm J, Rasmussen M, Maxted N (2016) In situ and ex situ conservation of priority crop wild relatives in Norway. Conserv Biogeogr 22:1112-1126. https://doi.org/10.1111/ddi.12470

Ramírez-Villegas J, Khoury C, Jarvis A, Debouck DG, Guarino L (2010) A gap analysis methodology for collecting crop genepools: a case study with Phaseolus beans. PLoS ONE 5(10):e13497. https://doi.org/10.1371/journal.pone. 0013497

Royal Botanical Gardens-KEW (2017) KEW herbarium -specimens. Richmond,London, United Kingdom. https:// specimens.kew.org/herbarium. Accessed 16 June 2017

Shire River Management Programme (2017) Strengthening the information base of natural habitats, biodiversity and environmental services in the Shire Basin: Regeneration potential studies and Management recommendations. LTS International Limited, Draft Report

Taylor GN, Kell SP, Holubec V, Parra-Quijano M, Chobot K, Maxted N (2017) A systematic conservation strategy for crop wild relatives in the Czech Republic. Divers Distrib 23:448-462. https://doi.org/10.1111/ddi.12539

UN (2015) United Nations: Sustainable Development goals 2015-2030. https://www.un.org/sustainabledevelopment/ sustainable-development-goals/. Accessed 6 Nov 2018

UN (2017) United Nations: The world Population Prospects: The 2017 Revision, Department of Economicsand Social Affairs.https://www.un.org/development/desa/ publications/world-population-prospects-the-2017revision.html. Accessed 21 June 2018

UN (2019) United Nations. Department of Economic and Social Affairs. United Nations: https://population.un.org/wpp . Accessed 27 July 2019

UNDP (2019) United Nations Development Program. https:// www.undp.org/content/undp. Accessed 27 July 2019

UNEP-WCMC (2019) The World Database on Protected Areas (WDPA), Cambridge, UK. https://www.protectedplanet. net/. Accessed 4 Jan 2019

Vincent H, Wiersema J, Kell S, Fielder H, Dobbie S, CastañedaÁlvareza NP et al (2013) A prioritized crop wild relative inventory to help underpin global foodsecurity. Biol Conserv. https://doi.org/10.1016/j.biocon.2013.08.011

Publisher's Note Springer Nature remains neutral with regard to jurisdictional claims in published maps and institutional affiliations. 